\title{
VERDADE, DESVELAMENTO E SER-COM: O ENTENDIMENTO COMPARTILHADO DO DASEIN
}

\author{
Lauro Ericksen ${ }^{1}$ \\ Universidade Federal do Rio Grande do Norte (UFRN) \\ (D) https://orcid.org/0000-0002-4195-1799
}

\begin{abstract}
RESUMO:
Apresenta-se o tópico da verdade, em Martin Heidegger, ao explorar a relação existente entre o desvelamento do ente e a possibilidade desse entendimento da verdade ser compartilhado nos meandros coletivos do Dasein com os outros. Metodologicamente, adota-se a crítica da metafísica empreendida por Heidegger e observa-se que é possível traçar o entendimento de que a verdade, a partir do desvelamento do ente, é o ponto de convergência entre o Dasein e a forma como ele se relaciona com os outros que lhe são semelhantes (co-Dasein). Objetiva-se, primariamente, desenvolver os conceitos de formas de vida autêntica do Dasein em suas disposições comunitárias, em seu modo de ser coletivo, promovendo o entendimento "intersubjetivo" mútuo a partir do enfoque ontológico dado pelo filósofo. Como resultados do trabalho, observa-se que o estudo do sercom os outros é imprescindível para que o entendimento do Dasein em toda a sua totalidade tanto em suas possibilidades hermenêuticas de ser-si-mesmo quanto em possibilidades mais alargadas de uma compreensão coletiva.
\end{abstract}

PALAVRAS-CHAVE: Metafísica; Ontologia; Verdade; Desvelamento; Dasein.

\section{TRUTH, ALETHEIA AND BEING-WITH: DASEIN SHARING ITS UNDERSTANDING}

\begin{abstract}
:
It discuss the truth as an important topic, in Martin Heidegger's philosophy, pointing the relation between the unveiling of the being and the possibility of shared and collective understanding of the truth, among Dasein and the others. Methodologically, it adopts the critique of the metaphysics employed by Heidegger and it observes that it is possible to design the shared truth as
\end{abstract}

\footnotetext{
${ }^{1}$ Doutor em Filosofia pela Universidade Federal do Rio Grande do Norte (UFRN), Rio Grande do Norte - Brasil. E-mail: lauroericksen@yahoo.com.br

Verdade, desvelamento e ser-com: o entendimento compartilhado do dasein - Lauro Ericksen
} 
a convergence point for everyone, being Co-Daseins in its reciprocal relation. This paper aims, primarily, to improve the heideggerian concept of authentic Dasein's life form, in its communitarian ways, promoting the "intersubjective" understanding from an ontological view. Its results suggests that the study of the "being-with-others" is something urgent to the understanding of Dasein in its total philosophical aspects, such as its true understandings of itself, as an hermeneutical venture of this topic and also in some more wide perspectives of collective understanding of the truth as it could be shared with others.

KEY-WORDS: Metaphysics; Ontology; Truth; Unveiling; Dasein.

\section{Introdução}

O presente trabalho tem como temática principal o tratamento dado por Martin Heidegger à questão da verdade na principal obra da primeira fase do seu pensamento, "Ser e Tempo". A partir da retomada da gênese grega (oriunda de Parmênides) segundo a qual a verdade é desvelamento, há de se buscar a possibilidade de uma verdade que seja possível de ser colocada nos meandros coletivos, ou seja, naquilo que o Dasein compartilha com os outros.

Os objetivos do trabalho se focam na possibilidade de traçar um seguimento hermenêutico pouco explorado dentro da filosofia heideggeriana, que é, justamente, a ascensão de uma compreensão coletiva (ou comunitária) do Dasein a partir daquilo que se desvela como verdade para ele. A partir do entendimento anti-metafísico (ou, melhor dizendo, no contexto de crítica à metafísica) empreendido por Heidegger, a remodelagem da verdade como desvelamento auxilia nessa tarefa de dar uma dinâmica ontológica ao relacionamento existente entre o Dasein e os outros que lhe são semelhantes.

Metodologicamente, o trabalho se foca precipuamente na obra em referência acima, mas também faz o percurso de analisar outras obras escritas no mesmo contexto interpretativo da primeira fase do pensamento de Heidegger, como "Introdução à Filosofia" e "Parmênides", sempre buscando auxilio em comentadores do filósofo em tela para dar um maior enriquecimento na pesquisa do tema escolhido.

Como resultados, obteve-se que o empreendimento heideggeriano de um novo projeto crítico da metafísica encontra em suas possibilidades o entendimento fundamental, e fundado na própria concepção de Dasein, que a questão do homem, e de sua intersubjetividade, por conseguinte, deve ser compreendida dentro do contexto coletivo em que o Dasein se relaciona com os outros, pois, é a verdade que aí se desvela que será a verdade para o Dasein, isto é, a verdade coletiva e comunitária que compartilhada entre ele 
e o outro é capaz de desvelar o ente, adequando-se, desta forma, ao tratamento ontológico por ele dispensado ao tema em relevo.

\section{A verdade como desvelamento para Heidegger}

Em Ser e Tempo, Heidegger busca tratar da questão de como a verdade se apresenta e como ela está correlacionada com a questão da realidade, um dos tópicos "metafísicos" por excelência, dentro do contexto tradicional da história da filosofia. Assim sendo, buscar-se-á na presente seção, brevemente, discutir a proposição heideggeriana da impossibilidade da adequatio na busca da verdade (como ocorre em na referida obra do filósofo alemão em comento), dada a sua inconclusiva assertiva sobre a realidade, para em seguida analisar a possibilidade do encontro da verdade por meio do conceito do ser-com. Assim, o tema da verdade, ao menos em Ser e Tempo, não está diretamente relacionado com o "ser-com", todavia, é importante que haja uma seção de introdução a esse tema para que ele possa ser entendido com maior clareza, afinal, apontamentos sobre a verdade na concepção de Heidegger serão necessários quando, na seção subsequente, for feita a conexão entre a verdade e a compreensão do Dasein a partir do compartilhamento, de modo que se o tema não for devidamente colocado propedeuticamente nessa seção ele poderá não ser entendido em sua total extensão a seguir.

O principal conceito combatido por Heidegger em sua análise antimetafísica perpetrada na obra em comento reside no ataque ao tradicional conceito da essência da verdade consistir na concordância entre o juízo e seu objeto. Isto é, ele contesta vorazmente a concepção de que o lugar da verdade é o enunciado (ou seja, o juízo). Partindo da premissa de que a separação promovida pela dúvida hiperbólica de Descartes, a qual gera indiscutivelmente a dicotomia do sujeito contraposto ao objeto ${ }^{2}$, é na verdade uma falácia, Heidegger começa a questionar a existência de uma adequação entre o discurso do sujeito e a sua referente indicação objetiva. Para o filósofo alemão em tela, não há como se ter nenhuma certeza dos enunciados tratados nessa perspectiva da adequação entre o sujeito e o objeto, pois, se assim fosse embasada qualquer concepção filosófica sobre esse tema, de maneira inexorável, haver-se-ia de se recair nos meandros da metafísica. Desta feita, o seu escopo consiste em superar esse esquecimento

\footnotetext{
${ }^{2}$ Como bem salienta Glenn Walter Erickson (1976, p. 34), Heidegger rejeita a aplicação de uma distinção entre "sujeito" e "objeto" para o homem no nível mais primordial ou originário de interpretação, mas ainda assim aceita o núcleo da ideia kantiana que a "objetividade" do "objeto" deve ser vista em termos de "subjetividade" do "sujeito".
} 
da questão do $\operatorname{ser}^{3}$ (oblivion of the being ${ }^{4}$ ), calcada na distinção do esquecimento entre o ser e aquilo que é (DREYFUS; WRATHALL, 2005, p. 123), para que se possa perscrutar uma definição de verdade que não esteja atrelada à tradição metafísica ${ }^{5}$ que tanto tratou de entificar, através dos juízos de adequação, o próprio ser.

Desta feita, observa-se, inelutavelmente, que Heidegger está a criticar de maneira incisiva toda a tradição calcada no elemento racional de validade da assertiva da verdade que conjuga a realidade a partir de uma adequação entre um enunciado e seu objeto. Heidegger vai à busca de um sentido de verdade ainda mais originário, o qual está para além da mera concordância, no qual a enunciação e a coisa se conformam, ela se encontra na abertura do desvelamento, onde o ente se mostra, em sua abertura, ou seja, está no âmbito de aparição do ente, onde o ser do ente o Dasein se encontram (MICHELAZZO, 1999, p. 139). Essa é a base para o desenvolvimento, ainda filosófico, da verdade para Heidegger, pois ele lança as bases para uma definição de verdade, mas que não se encontra atrelado às conceituações metafísicas, sendo um pensamento, portanto, eminentemente anti-metafísico ${ }^{6}$.

Por causa dessa retomada da raiz grega da verdade como desvelamento, a verdade para Heidegger é tida como uma "verdade declarativa" (APEL, 2000, p. 49), haja vista que ela segue o esquema segundo o qual uma declaração é verdadeira quando ela revela e "descobre" (no sentido de retirar aquilo que o está encobrindo) o ente de maneira

\footnotetext{
3 Para Heidegger, o esquecimento do "ser", compreendido com um problema eminentemente filosófico, deu-se desde Platão e Aristóteles, de modo que o seu esforço consiste em resgatar o sentido grego antigo de verdade, tanto que ele retoma Parmênides para explicar a questão da verdade como desvelamento. Como bem exemplificam Catalin Partenie e Tom Rockmore (2005, p. XXII), para Heidegger, o primeiro esquecimento do sentido original do ser foi perpetrado por Platão e sua concepção de "ideia" (eidos), a qual inaugura a era do niilismo, como uma forma de esquecimento do ser. Todavia, há de se destacar que o esquecimento da questão do ser foi mais intensificado ainda na época moderna, em torno do século XVII (PYLKKÖ, 1998, p. 149), por causa do extremo foco cientificista dessa época e por causa da sua disseminação tecnológica, o que ajudou a encobrir ainda mais a questão do ser propriamente dita.

4 O termo em alemão utilizado por Heidegger para oblivion of the being é Seinsvergessenheit. Tal étimo denota, além da tradução literal como sendo o "esquecimento do ser", a capacidade de se conseguir perpetuar tal esquecimento.

${ }^{5}$ Ressalte-se apenas que por tradição metafísica no decorrer do trabalho em curso deve-se entendê-la como sendo a tradição que perpetua o esquecimento do ser (ou seja, quase que a totalidade do pensamento filosófico historicamente construído), para tanto, trilham-se nesse sentido os apontamentos de Herman Philipse (1998, p. 382) acerca desse tema.

${ }^{6}$ A ratificação desse posicionamento anti-metafísico é bem feita por Rubens Russomano Ricciardi (2005, p. 12) ao asseverar que: "através da conceituação de verdade como $\alpha \lambda \eta ́ \theta \varepsilon \iota \alpha$, Heidegger questiona a concepção de linguagem entendida tão somente como estrutura em meio às tradições metafísicas". Ou seja, Heidegger ao criticar a metafísica dominante expõe a questão de como a linguagem é estruturante do pensamento para opor sua crítica a essa sistemática de origem cartesiana.
} 
tal como ele é em si mesmo. Sendo certo que Heidegger amplia essa definição de verdade no sentido de ser conceito do "estar-aberto" do Dasein ou de uma "clareira" do ser, a partir de elementos segundo os quais o Dasein desvela o ente para si e com ele passa a interagir, até mesmo coletivamente em seu círculo de interação.

Apesar de sua crítica ser inicialmente dirigida ao Grande Embusteiro (René Descartes), pela separação essencial que o filósofo francês faz entre a concepção dualista de "mente" e de "corpo" como fundamento metafísico de suas obras de maior destaque, ele também mira em outros filósofos mais recentes para desconstruir a conceituação metafísica de seu tempo, de modo que não se abstém de criticar as conceituações de Immanuel Kant e Wilhelm Dilthey sobre os desdobramentos da razão sobre a necessidade de uma adequação para se atingir uma verdade (HEIDEGGER, 2008c, p. 99), ou ao menos, na obra kantiana, de se alcançar um método de representação (por meio dos fenômenos) daquilo que se busca descobrir na essência. O cerne da interpretação heideggeriana do Dasein não consiste em apenas observar as repercussões dos fenômenos (tal como Kant propõe), a sua metodologia fenomenológica, advinda das lições de Husserl, possui um viés diferente. Essa perspectiva se torna ainda mais específica quando se combina a questão fenomenológica o elemento existencial. Essa conjunção é operada na proposta da analítica existencial, a qual escrutinada por Heidegger em Ser e Tempo e serve como norteamento metodológico para se analisar todos os modos de ser por ele propostos.

Nesse passo, a verdade como desvelamento no sentido heideggeriano, como bem esclarece David Farrell Krell (1986, p. 20), tem uma tarefa bastante definida, afinal ela requer que Heidegger a coloque como sendo, concomitantemente prática e "vivida" no mesmo nível de uma verdade teorética, cognitiva, a qual finda por trazer a tona o confronto do ente desvelado com a finitude, em sua faceta fática, histórica, de "vida-emprocessamento" ". Ou seja, a partir dessa acepção da verdade se descortina um novo horizonte de entendimento do Dasein, pois todas essas idiossincrasias de historicidade e de experiências vivenciadas são até ele postas, mutuamente, de forma prática e teorética.

No entanto, é de grande valia para a presente abordagem destacar que em Ser e Tempo Heidegger não aprofunda a questão da verdade e o descobrimento da realidade tanto quanto ele o faz em outras obras suas, como nos escritos em que ele analisa o pensamento de Parmênides, ou em outras fases do seu pensamento acerca da Origem da Obra de Arte, tópicos referentes a outras formas de Heidegger de analisar a questão do ser e da verdade. Bem porque na obra de referência da primeira fase do seu

\footnotetext{
${ }^{7}$ No texto original Krell se vale do termo "life-in-process" para designar essa forma de relacionamento entre a finitude e a verdade em Heidegger. Termo este que findou por ser traduzido como "vida-em-processamento" ou "vida-em-curso", o qual evidencia claramente o caráter "vivido" (ou "vivenciado) da verdade como desvelamento.
} 
pensamento (qual seja, Ser e Tempo) ele conclui que a verdade se dá a partir da descoberta operada pela abertura do ser-no-mundo (In-Sein). Destarte, ele assevera que os fundamentos ontológicos-existenciais do próprio descobrir é que mostram o fenômeno mais originário da verdade (HEIDEGGER, 2008c, p. 291). Ou seja, sem a abertura do ser, seja na sua atividade de inserção ou na sua fundamentação existencial, não há possibilidade para que a própria verdade se desvele.

Percebe-se, a partir da exposição feita, que Heidegger combate a exposição metafísica calcada na tradição que prima pela racionalidade como ordenadora do ser. Por isso que ele desenvolve um novo índice de indeterminação de possibilidades, o qual, por ventura, o "ser humano" se insere, algo que ele denominou como sendo o Dasein. Nesse horizonte, a concepção heideggeriana a esse respeito é bem salienta por Roberto Novaes de Sá (2004, p. 2) ao dizer que: "O ser do homem é pura abertura de sentido, Dasein, ser-aí, existência, ser-no-mundo”. Destarte, segundo as pontuações de Heidegger, não há mais um sujeito encarcerado nos meandros da metafísica tão perpetuada na tradição da filosofia, há uma desconstrução dessa conceituação para que surja um novo elemento filosófico em seu pensamento, o Dasein. A desconstrução encetada por Heidegger é necessária para que se possa abandonar a visão restritiva do ser, haja vista que desde o advento do seu esquecimento, aliás, do esquecimento do seu sentido mais originário, na época da Grécia antiga, que a ontologia esteve relegada ao puro esquecimento, ainda mais em voga com o idealismo dominante no período em que Heidegger escreveu seus textos principais sobre esse tema.

Não obstante, sem que dessa determinação existencial ele tenha extraído algum elemento biológico precipuamente válido que sirva de fundamento desta colocação. Essa indicação ontológica do Dasein, por não ser algo biologicamente estatuído, é que permite a própria definição de um Dasein coletivizado na perspectiva comunitária do ser-com. Se o Dasein estivesse atrelado, até mesmo que de maneira atenuada, ou simplesmente formal, a um componente estrutural biológico, a compreensão de um Dasein em sua expressão comunitária se restaria deveras comprometida, pois não haveria uma unidade no aspecto biológico que servisse para a justificação desse argumento de maneira minimamente válida, como ele o é sem essa dependência "físicista".

Desta feita, há de se compreender que o Dasein não está submetido à categorização do $\operatorname{logos}$ aristotélico, basicamente por que ele está apenas contido em suas possibilidades, são essas possibilidades que caracterizam a sua abertura de mundo, e não mais a contenção a uma categorização metafísica. Não existe mais uma consciência ${ }^{8}$ (Bewusstsein) que sirva como

\footnotetext{
${ }^{8}$ Uma consciência atrelada à concepção de um "sujeito" que perscruta os "objetos" que se encontram dispostos no mundo físico não mais serve aos propósitos de Martin Heidegger. Por isso mesmo que ele desconstrói essa ideia de uma consciência que apenas introjeta a
} 
fundamento do ser. Não obstante, a sistemática de possibilidades fornecidas pelos aspectos decisórios do Dasein é o elemento determinante que possibilita que se fomente o caráter anti-fundacional (ORKRENT, 1988. p. 223) de pensamento precipuamente anti-metafísico de Heidegger. As múltiplas possibilidades que o Dasein possui em se decidir são a única perspectiva que ele possui, de modo que não há mais nada que possa servir de assentamento para a sua explicação, não há mais nada que seja substancial ou a priori para mantê-lo em conexão com o seu próprio mundo (aí). Essa conclusão de que não há mais uma consciência, previamente fundada em elementos a priori, como defendem os filósofos precedentes já citados nessa exposição (tal como Descartes e Kant, para citar os mais influentes), é o fio condutor das possibilidades existenciais do Dasein, tanto em sua esfera individualizada (que, nesse momento, serve apenas como norte interpretativo da questão do ser e de sua contraposição aos argumentos filosóficos dos pensadores referenciados) quanto em sua denominação comunitária, que é o cerne do debate por ora encetado.

Sem esse desprendimento da tradição filosófica que se encontra calcada no fundamento da consciência não há como se abranger todo o argumento anti-metafísico de Heidegger, e, consequentemente, não há como se perfazer os subsequentes delineamentos acerca do caráter comunitário dos aspectos decisórios do Dasein em sua expressividade existencial do sercom. Afinal, para Heidegger, ser um "ser humano" (o Dasein, em última e mais singela instância) é literalmente estar na verdade que é por ele mesmo compreendida, ou seja, é ter entendimento suficiente de algo que é verdade para ser errado acerca de algo que ele sabe ser verdadeiro, para si, ao menos (KELLER, 2004, p. 100). Essa noção de verdade distancia-se bastante das versões de verdade apregoadas pela tradição filosófica, e, por isso mesmo, ela é capaz de dar sustentáculo a uma verdade compartilhada comunitariamente, a qual serve de encalço para que o Dasein se compreenda e mutuamente compreenda os outros segundo a verdade que descerra e desoculta o ente, de modo que eles próprios se compreendem, verdadeiramente em si mesmos.

Em síntese, há de se asseverar que no sistema anti-metafísico de Heidegger não há congruência entre o enunciado e o objeto (isto é, não há adequatio) de maneira que o que pode haver é apenas o desvelamento da verdade, a partir da abertura do ente, para a compreensão de ser; ser-nomundo e ser-com os outros - afinal, em última instância, o ser-com é a instância comunitária do modo de ser-no-mundo (KIESEL, 1993, p. 295) -, dentro da perspectiva ontológica do Dasein. Somente por se ter esse enunciado conclusivo em referência, é que se afigura possível promover um horizonte de comentários e de interpretações mais específicas acerca do

percepção desses objetos como se eles estivessem meramente postos no mundo à serventia do sujeito que os perscruta. 
tema em comento, e, por conseguinte, poder se fazer um aprofundamento do tópico do Dasein em comunidade (ser-com) em referência com elementos de empreendimento da verdade a ser por ele analisada em termos fenomenológicos-existenciais.

\section{0 ser-com e a verdade: 0 descerramento da verdade através do compartilhamento}

Na sua obra Introdução à Filosofia, Martin Heidegger aponta que, como modo autêntico de ser-com os outros, o próprio Dasein se apresenta "descerrado" junto aos outros. Esse descerramento não quer dizer de maneira precípua que o Dasein é apreendido em sua totalidade por outro Dasein (por apreender outro Dasein deve ser compreendido no sentido de que o Dasein teria a capacidade de apreender um ser que em si mesmo já está descerrado). Ao se utilizar do termo "descerrado" Heidegger quer chamar atenção para o modo que se dá a abertura existencial entre o Dasein e o outro dentro da dinâmica do ser-com o outro e as possibilidades existenciais daí decorrentes.

A conjecturação de uma possibilidade autêntica, tal como descrita anteriormente, significa que o Dasein descerra a si mesmo, ele próprio induz a abertura em suas interações habituais. Nesse processo de descerrar ele finda por promover, na abertura do seu ente, o próprio desvelamento da verdade (HEIDEGGER, 2008c, p. 254), a qual não mais se encontra inserta nas denominações tradicionais da tradição filosófica, como veritas tratada por ele em sua denominação grega de Alétheia (transliterado como

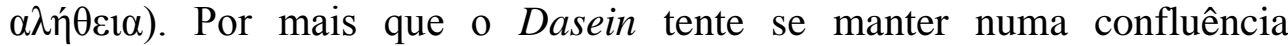
inautêntica de seu ser, ao não se descerrar para os outros, não se afigura a possibilidade que ele não se descerre ao menos para si (HEIDEGGER, 2008a, p. 143). Destarte, esse entendimento demonstrado por Heidegger se aproxima muito da concepção grega atribuída a Sócrates da inscrição contida no oráculo de Delfos que foi usualmente traduzida pela tradição filosófica por "conhece-te a ti mesmo". Não obstante, Heidegger, de maneira condizente com os seus ensinamentos em outras obras suas, indica que, ao menos, através desse descerramento para consigo mesmo, chega-se ao adágio de conhecer-se a si mesmo. Igualmente, mesmo que se tente se afastar e manter-se obscuro para os demais entes presenciais, para si mesmo, o conhecimento e o descerramento, é uma premissa existencial da qual não se pode fugir, ausentar-se ou simplesmente ignorar: o descerramento do si próprio é um conhecimento de si que o Dasein não é capaz de ocultar para ele mesmo, ainda que almeje, de alguma forma, esconder tal fato para os outros.

Esse apontamento, todavia, não conduz à percepção de que haja uma "consciência" de si mesmo, no sentido de uma "autoconsciência" apregoada por Descartes (como o sujeito cognoscente) que posteriormente foi tão 
debatida pelo idealismo alemão. A verdade, como está dito, não é do ente denominado de homem, mas do ser. Em relação à dinâmica própria da revelação do ser, o homem não desempenha "a função de sujeito transcendental" que tem o "poder das chaves para 'abrir' o verdadeiro e o não verdadeiro" (NUNES, 1999, p. 80). Não obstante, é importante dizer que esse ponto acerca da existência (ou inexistência, por assim dizer) é bastante relevante e deve ser escrutinado com cuidado, principalmente em função do conceito de subjetividade tão apregoado durante períodos pretéritos da história da filosofia, momentos em que o conceito de consciência imiscuído na dicotomia objeto-sujeito impediu uma correta análise acerca da verdade e da própria "subjetividade" por assim dizer.

Nessa toada, há de se compreender que o fato de o Dasein descerrarse para si mesmo não conduz à conclusão de que ele se compreenda de modo absoluto, não há um completo saber de si mesmo ou um voltar-se para si, como se o "sujeito" se torna seu próprio "objeto" e assim encontrasse a verdade. Se assim o fosse, não se restaria superada a questão da adequação entre o juízo e o enunciado, ou seja, a verdade permaneceria inserida no juízo e a dicotomia do sujeito e do objeto se contrapondo permaneceria válida. Aliás, condições de validade e interconexões de verdade entre o discurso é tudo que o modelo metafísico almeja para se perpetuar como molde filosófico.

O descerrar do Dasein deve ser compreendido como uma determinação do seu "ser junto a..." (ideia de abertura do Dasein para seu próprio mundo). Desta maneira, ele não se torna um objeto para si mesmo, nem ao menos se torna manifesto para si mesmo, ainda que ele se conheça, as suas possibilidades existenciais não se encontram predeterminadas, por isso que ele não é, sequer, manifesto para si mesmo, haja vista que, se o fosse, grande parte - senão a própria totalidade de suas escolhas e decisões (HEIDEGGER, 1998, p. 6) - restaria pré-concebida em suas escolhas, e, portanto, a sua abertura para com o mundo seria algo aparente não operável em nenhum sentido prático. $\mathrm{O}$ ato de descerrar ocorre ao mesmo tempo em que se compreende a verdade desvelando o ente, sendo certo asseverar também que o Dasein compreende o próprio ocultamento do ente, ou seja, a "não-verdade", no momento em que compreende a sua verdade. O Dasein, assim, encontra-se, concomitantemente na sua verdade e na sua nãoverdade, no mesmo sentido de compreensão que ele se avia e se desvela. Tal

\footnotetext{
${ }^{9}$ Há quem aponte, como o faz William Desmond (2000, p. 485), que Kierkegaard já endossava uma conceituação de "não-verdade" ao reverter a crença consagrada na ideia tradicional de que a verdade é objetiva, alcançada apenas pela superação da instabilidade da subjetividade. Esse é mais um dos argumentos que fomentam o crescimento e a solidificação do entendimento defendido nessa dissertação de que há uma conexão filosófica importante no entendimento da subjetividade entre Kierkegaard e Heidegger, sem que seja necessário se levantar prioritariamente a questão da angústia para se fazer uma relação entre esses dois filósofos, algo que será mais detidamente abordado e escrutinado em capítulos vindouros.
} 
aspecto calcado em certa compreensão "dual ${ }^{10 "}$ ocorre porque a sua exposição de verdade, contém em si mesmo aquilo que não se está devidamente à mostra que é a sua forma de se ocultar e não se mostrar, ou seja, contém a não-verdade nessa composição de velar-se e desvelar-se perante os eventos que demandam essa forma de apresentação do Dasein em seu contexto de verdade, tal como descrito na presente análise.

Como já mencionado acerca do "aí" que o Dasein carrega, toda essa abertura de mundo é que possibilita a apreensão originária do Dasein do seu próprio descerramento. O Dasein não se torna simplesmente manifesto, a partir daí que o ente que ele desvela finda por ser descoberto, tampouco o mundo que se encontra inserto no seu "aí" é simplesmente posto à prova e manifestado tal como se fosse uma mera repercussão fenomênica de algo que já se encontra previamente determinado no próprio Dasein. Pensar assim equivale a dar razão ao entendimento kantiano de instâncias a priori da razão e da sensibilidade, algo que é visto de maneira totalmente diferente por Heidegger, sem que haja essa entificação do ser e da verdade, promovendo uma observação mais acurada da própria abertura inerente ao Dasein, e principalmente a influência das interações comunais no ser-com o outro. A verdade, no sentido heideggeriano, assim como enuncia Peyman Vahabzadeh (2003, p. 149): se mostra no conflito entre o ocultamento e o desocultamento, entre a presença ${ }^{11}$ e a ausência. Ou seja, ela é permeada, e não simplesmente dada, correspondida ou adequada a uma sistemática de aprisionamento do ente em seu próprio ser.

Ao concatenar suas ideias acerca do "aí" e do descerramento do Dasein, Martin Heidegger chega a utilizar o termo "esfera" para se referir metaforicamente ao círculo de apresentação do supracitado "aí". Ele diz que ao se descerrar junto aos outros, o Dasein se "movimenta no interior da esfera do aí". Essa representação pictográfica tem um papel didático bastante claro e bem definido, haja vista que é mais fácil se adquirir uma representação gráfica de como esse "aí" é concebido do que simplesmente divagar sobre as formas de apresentação dessa essência de mundo que o Dasein se encontra existencialmente dentro. É a partir dessa colocação que ele consegue expor, representativamente, a forma que o descerramento do Dasein se dá em suas possibilidades dentro do círculo de interações do seu próprio mundo.

\footnotetext{
${ }^{10}$ Por "dual" deve-se compreender apenas a possibilidade variável de a verdade se dar conjuntamente com a não verdade, não se devendo tomar este termo na acepção maniqueísta de verdade como oposição a um enunciado válido ou inválido do ponto de vista meramente lógico.

${ }^{11}$ Saliente-se apenas que "presença", nessa sentença, não adquire o sentido de Dasein, ou ser-aí, dado por Márcia Schüback em sua tradução de Ser e Tempo para o português, de modo que tal termo é utilizado por Vahabzadeh no sentido mais comum de "aparecimento" propriamente dito e não em outro sentido mais abstrato que o mencionado.
} 
Obviamente que o conceito de espacialidade aqui elencado não corresponde à dinâmica espaço-temporal cartesiana, o espaço aqui referido é a espacialidade incontida do Dasein e seu rasgo de movimentação dessa espacialidade, muito embora esse não seja o tema central do presente trabalho, é bastante importante clarificar essa passagem para que o conteúdo total seja mais bem compreendido. Assim, essa espacialidade, e a sua aludida referência gráfica, apenas fornecem as possibilidades de abertura, e, consequentemente, aos eventos que essa abertura possibilita, tanto no âmbito individual de desvelamento do ente para o Dasein, quanto naquilo que se refere às possibilidades comunitárias mais abrangentes.

Nessa dinâmica expositiva do Dasein ao se descerrar e encontrar faticamente outro Dasein, isso representa que o outro também não está meramente "aí" em sua espacialidade. Deve-se compreender que ao contrário do que se possa comumente pensar, o outro Dasein encontra-se essencialmente co-presente - ou co-Dasein, devendo apenas se ter em conta a ressalva feita por Richard F. H. Polt (2005, p. 107) para quem esse coDasein nunca é, estritamente falando, intramundano, e, sim, no-mundo, em recíproca existência com os demais - para com o outro Dasein que se descerrou. Assim sedo, há de se ter em conta que ambos se inserem no mesmo círculo de manifestação.

Não obstante, há de se deixar assente que a supracitada dinâmica de estar junto a outro Dasein só se afigura possível em virtude do mesmo primado ôntico-ontológico que ambos apresentam. Na medida em que o Dasein apresenta a existência como manifestação de sua essência, indubitavelmente, o seu "aí" que é com eles carregado demonstra a conjunção fática e presente de seu círculo de possibilidades. Assim, o que é por eles compartilhado a partir do descerramento de um para com o outro é esse círculo, esse círculo é o elo de compartilhamento entre eles.

Só é possível haver esse compartilhar (ou o "com" do "ser-com") a partir da existência do "aí", afinal, dos muitos que se descerram sendo um ser junto a outros é que formam o ser-com propriamente dito. O ser-com não é um modo de ser do Dasein simplesmente por subsistir de maneira "próxima" ao ente, ele simplesmente não se encontra onticamente colocado em sua justaposição para favorecer essa possibilidade de compartilhamento. Como já enunciado, essa forma de apresentação, esse modo de ser, portanto, é muito mais originário, e envolve o modo de ser próprio de um Dasein com o outro, ou seja, ser-um-com-o-outro.

Deste modo, a distância fática existente o Dasein e o outro não é o elemento fulcral para se determinar a possibilidade de existência do sercom. Como bem fala Heidegger em Ser e Tempo acerca do que ele denomina de afastamento (Abständigkeit), esse espaço ocupado pelo Dasein não se circunscreve a mera distância factual. O afastamento do Dasein ocorre basicamente em sua apresentação inautêntica do impessoal (Das Man), de modo que onticamente se está mais próximo do ente, embora 
ontologicamente o inverso tenha ocorrido, ou seja, houve o distanciamento do referido ente.

Nesse sentido, a proximidade ocorrida no ser-com não é algo simplesmente espacial, afinal, se o fosse, o círculo de manifestação do compartilhamento do Dasein não seria, justamente, o seu "aí". Não existe a dualidade interior e exterior, para qual o descerramento do Dasein se introjete ou se exteriorize. O Dasein já se encontra fora, uma vez que está junto aos outros como bem menciona Heidegger (2008a, p. 146), "ele é saindo" de si. Essa "exteriorização", possivelmente compreendida como o elemento de expressão do ente, é algo que se manifesta mais na temporalidade da apresentação do Dasein, do que na sua competência espacial, como já dito. De modo que não há nenhuma representação espacial a ser feita dessa expressão do ente, ele apenas se desvela, através do seu "aí", de uma maneira não propriamente espacial.

Esse sair de si de maneira alguma depreende que haja um "interior" do qual ele seja expurgado, o movimento "para fora" que ele realiza é ele mesmo, como ele já carrega propriamente o seu "aí", esse fora não é nada mais que o círculo de manifestação do seu "aí", de modo que também não é algo que lhe seja estranho. Por ele ser essencialmente Dasein ao sair de si, o co-pertencimento aos outros finda apenas a ser uma maneira de ele mesmo se exteriorizar o seu "aí" para com os outros.

Diante do panorama apresentado, há de se compreender que o sercom é essencialmente um modo de ser do ente mesmo que ele não apresente faticamente a presença de outro Dasein. Importante destacar que na empreitada do Dasein de se descerrar a si mesmo e aos outros ocorre a sua inserção de ser descobridor no mundo. $\mathrm{O}$ descerramento do ser pertence a algo compartilhado, algo que o Dasein transparece em seu modo de ser mais originário. Esse descerramento sempre promove a abertura de algo que já era minimamente compartilhado pelo Dasein.

Assim sendo, afigura-se deveras esclarecida a possibilidade de compartilhamento do "aí" do ser-com na perspectiva heideggeriana (afinal, o aí é o Da do Dasein). Nesse sentido, apenas o "com-partilhar" da verdade desvelada do Dasein é que permite que a conjuntura dele para com os outros seja algo feito de maneira originária. Quando se fala que isso ocorre originariamente deve-se depreender que essa conjunção do "aí" compartilhada e descerrada não se dá de maneira meramente factual.

Esse descerramento do Dasein, sob a perspectiva de que ele é ser-nomundo, e, portanto, ser-descoberto, leva ao entendimento de que no desvelamento que traz consigo o ente junto ao outro, aquilo que é desvelado é o próprio Dasein. Quando há o co-pertencimento de maneira autêntica entre os o Dasein e os outros, de maneira que o outro não passa simplesmente a ser compreendido como algo estranho a si, algo que lhe seja indiferente ou casualmente díspar. 
O desvelamento do ente dotado do caráter de Dasein - que em última instância é o próprio desvelamento do ente e encontro da verdade, uma vez que a verdade é capaz de mostrar o ente em si mesmo -, é algo já impregnado na dinâmica compartilhada do Dasein, isto é, não pode haver o descerramento nem muito menos a colocação do Dasein junto aos outros sem que o ente seja desvelado e, assim, a verdade seja mostrada ao outro. Há de se sublinhar que esse compartilhamento da verdade entre o Dasein e os outros é que lhe confere essa "proximidade" entre eles, afinal, o outro Dasein não lhe é estranho. Nesse sentido, como bem ressalta Romulo P. Pizzolante (2008, p. 51), "verdade e homem se imbrincam, num mesmo e se co-pertecem", não obstante essa confluência entre o desvelamento como verdadeiro e a sua relação com aquilo que o Dasein pode ser em sua abertura de mundo finda por conduzir ao entendimento que o outro, com quem se compartilha o mundo, está-se, com ele, compartilhando a verdade e que o seu pertencimento se dá de forma mútua.

O simples fato de cada um carregar univocamente o seu "aí" e de ser impossível se desfazer de tal "fardo", uma vez que, acompanhado do "aí" vem também a necessidade imperiosa de se decidir, algo que por vezes pode ser tormentoso. Nesse ponto que o descerrar do Dasein em compartilhamento da verdade é um modo de ser que auxilia a própria tomada de decisões do ente que se aproxima dessa maneira ontológica.

É nessa perspectiva que as possibilidades decisórias do Dasein não ficam relegadas ao plano da inautenticidade. Como Heidegger (2008c, p. 186) posteriormente vai discutir no parágrafo 27 da obra Ser e Tempo, essa tomada de decisões fica apenas congregada na sua apresentação do impessoal. Ou seja, dito de maneira mais clara, o fardo decisório fica imiscuído no ramo decisório da impessoalidade, da forma de apresentação inautêntica do Dasein que retira toda a compreensão ontológica dos acontecimentos para permanecer inerte na compreensão pré-ontológica do impessoal. As ponderações mais aprofundadas sobre esse tema serão objeto de estudo no quarto capítulo da presente dissertação, momento em que se poderá escrutinar melhor os seus pormenores filosóficos.

\section{Considerações finais}

Assim sendo, a verdade desvelada a partir do ser-com, em seu compartilhamento, promove a possibilidade decisória mais próxima do modo de ser originário do Dasein, que se afigure de maneira independente da inautenticidade do impessoal, afinal, ainda que o Dasein se encontre como ser junto aos outros, essa aproximação não se dá de maneira meramente ôntica, como inexoravelmente se procede nos domínios do impessoal, sempre tomado como primeira interpretação de mundo.

Por fim, há de se concluir que embora ainda haja um longo caminho a se trilhar na forma de interpretação da verdade compartilhada do Dasein 
em seu descerramento no ser-com, como interpretação de mundo descobridora, ao menos há de se compreender que o desvelamento do ente promovido por esse modo de ser é importante na compreensão ontológica do posicionamento do "aí" como elemento de espacialidade e de compreensão do próprio ente.

Esse compartilhamento da verdade não se distancia do modo da compreensão ontológica, tão cara a construção da autenticidade expositiva do Dasein, que, embora não tome um lugar privilegiado na metodologia da analítica existencial, finda por ser uma das perspectivas de escrutínio do modo de ser-com do Dasein. Algo que, conjugado com as premissas básicas da estrutura ontológica da preocupação, dá uma maior completude às formas conjuntivas e comunitárias de apresentação de coletividade do Dasein, expressando essa ligação existente entre a miríade de possibilidades a ele apresentadas em compasso com o desvelamento de ente. 


\section{Referências bibliográficas}

APEL, Karl-Otto. Transformação da filosofia. Trad. Paulo Astor Soethe. São Paulo: Loyola, 2000.

DESMOND, William. A Filosofia e seus outros: Modos do ser e do pensar. Trad. José Carlos Aguiar de Sousa. São Paulo: Loyola, 2000.

DREYFUS, Hubert; WRATHALL, Mark. A Companion to Heidegger. Malden: Blackwell, 2005.

ERICKSON, Glenn Walter. The Question of the Meaning of Being. Ann Arbor: UMI, 1976.

HEIDEGGER, Martin. A origem da obra de arte. Trad. Maria da Conceição Costa. Lisboa: Edições 70, 2007.

. Introdução à filosofia. Trad. Marco Antonio Casanova. São Paulo: Martins Fontes, 2008a.

Vozes, 2008b.

Parmênides. Trad. Sérgio Mário Wrublevski. Rio de Janeiro:

. Ser e tempo. Trad. Márcia Sá Cavalcante Schüback. 3. ed. Rio de Janeiro: Vozes, 2008c.

KELLER, Pierre. Husserl and Heidegger on Human Experience. Cambridge: Cambridge UP, 2004.

KIESEL, Theodore. The Genesis of Heidegger's Being and Time. Berkeley: California UP, 1993.

KRELL, David Farrell. Intimations of Mortality: Time, Truth and Finitude in Heidegger's Thinking of Being. University Park: The Pennsylvania State University, 1986.

MICHELAZZO, José Carlos. Do um como princípio ao dois como unidade: Heidegger e a reconstrução ontológica do real. São Paulo: Annablume, 1999.

NUNES, Benedito. Hermenêutica e poesia. Belo Horizonte: EDUFMG, 1999.

ORKRENT, Mark. Heidegger's Pragmatism: Understanding, Being and the Critique of Metaphysics. Ithaca: Cornell UP, 1988.

PARTENIE, Catalin; ROCKMORE, Tom. Heidegger and Plato: Toward dialogue. Evanston: Northwestern UP, 2005.

PHILIPSE, Herman. Heidegger's Philosophy of Being: A critical interpretation. Chichester: Princeton UP, 1998. 
PIZZOLANTE, Romulo P. A essência humana como conquista: O sentido da autenticidade no pensamento de Martin Heidegger. São Paulo: Annablume, 2008.

POLT, Richard F. H. Heidegger's Being and Time: Critical Essays. Lanham: Rowman and Littlefield, 2005.

PYLKKÖ, Pauli. The Aconceptual Mind: Heideggerian themes in holistic naturalism. Amsterdam: John Benjamins, 1998.

RICCIARDI, Rubens Russomano. Linguagem musical e processo criativo. In: MAC DOWELL, João A.; YAMAMOTO, Marcelo Yukio (Org.). Linguagem e linguagens. São Paulo: Loyola, 2005. p. 11-48.

SÁ, Roberto Novaes. As influências da fenomenologia e do existencialismo na psicologia. In: JACÓ-VILELA, Ana Maria; Ferreira, Ana Maria; FERREIRA, Arthur Arruda Leal; PORTUGAL, Francisco Teixeira (Org.). História da psicologia: Rumos e percursos. Rio de Janeiro: Nau, 2005. p. 216.

VAHABZADEH, Peyman. Articulated Experiences: Toward a radical Phenomenology of contemporary social movements. Albany: SUNY Press, 2003.

Autor(a) para correspondência: Lauro Ericksen, Universidade Federal do Rio Grande do Norte, Campus Universitário Lagoa Nova - Lagoa Nova, CEP 59078-970, Natal - RN, Brasil. lauroericksen@yahoo.com.br 